\title{
A One-Year Follow-Up of Two Ahmed Glaucoma Valve Models (S2 and FP7) for Refractory Glaucoma: A Prospective Randomized Trial
}

This article was published in the following Dove Press journal: Clinical Ophthalmology

\author{
Khaled Hamdi Elbaklish (D) \\ Wael Adel Gomaa (D) \\ Ophthalmology Department, Ain Shams \\ University, Cairo, Egypt
}

\begin{abstract}
Aim: To compare a range of clinical outcome variables (intraocular pressure, glaucoma medications, visual acuity, and complications) between two Ahmed glaucoma valve (AGV) models (S2 and FP7).
\end{abstract}

Methods: This was a prospective and randomized clinical trial. Fifty-six patients with refractory glaucoma were randomly assigned to be implanted with either a polypropylene (S2) or silicone (FP7) Ahmed glaucoma valve. The primary outcome measure was a surgical success, defined as an IOP $\leq 16 \mathrm{~mm} \mathrm{Hg}$ (without medication), and guarded success, defined as a controlled IOP $\leq 16 \mathrm{mmHg}$ (with medication). Failure was defined as when the IOP lay outside of the successful range on two consecutive visits $(>16 \mathrm{mmHg}$, despite medication). Results: Mean follow-up period was $398.42 \pm 12.34$ days (range, 380-420 days) for the S2 group and $401.75 \pm 9.78$ days (range, 385-420 days) for the FP7 group; these values were not significantly different $(\mathrm{P}=0.27)$. After 12 months of follow-up, the baseline IOP (45.42 $\mathrm{mmHg}$ ) fell significantly to $16.14 \mathrm{mmHg}$ in the $\mathrm{S} 2$ group $(\mathrm{p}<0.000)$; there was also a significant reduction in IOP in the FP7 group (from $44.17 \mathrm{mmHg}$ to $15.18 \mathrm{mmHg}$ in FP7 group, $\mathrm{p}<0.000$ ). At the last follow-up examination, the mean IOP in the S2 group was $16.14 \pm 3.18 \mathrm{mmHg}$, while that of the FP7 group was $15.18 \pm 2.75 \mathrm{mmHg}$; there was no significant difference between the two groups with this respect $(p=0.23)$. The mean number of medications used by patients in the S2 and FP7 groups was $2.92 \pm 1.27$ and $2.75 \pm 1.43$, respectively; there was no significant difference between the two groups with this respect ( $\mathrm{p}$ $=0.32$ ). There was no significant difference between the FP7 and S2 groups with regard to their relative success rate $(17.89 \%$ [5/28] versus $10.7 \%$ [3/28], respectively; $p=0.38)$.

Conclusion: Our data show that the S2 and FP7 models of AGV were both effective in lowering IOP and reducing the need for glaucoma medications. Although these two AGV models had similar dimensions, they were constructed from different materials. However, there were no significant clinical differences between the S2 and FP7 AGV groups after 12 months of followup. Furthermore, our data indicate that bleb encapsulation was the primary factor responsible for failure rate and the need for glaucoma medication in both the S2 and FP7 groups. Our analysis further indicates that the S2 and FP7 Ahmed valves are associated with a high risk of failure when considered as a first-line therapy for cases experiencing trabeculectomy.

Clinical Trial Registration: NCT04214847.

Keywords: Ahmed glaucoma valve, S2, FP7, IOP, encapsulation

\section{Introduction}

Glaucoma drainage devices have become a more favored option than the combination of trabeculectomy and anti-metabolites for the controlling intraocular pressure (IOP). ${ }^{1}$
Correspondence: Khaled Hamdi Elbaklish Ophthalmology Department, Ain Shams University, Abbasi, Cairo, Egypt

Tel +201000057550

Email khaled.hamdy62@yahoo.com 
Initially, these devices drain aqueous humor from the anterior chamber to the posterior plate; the aqueous humor then crosses the pseudocyst formed around this plate and is subsequently absorbed by venous capillaries, or the lymphatic system. $^{2-5}$ The Ahmed valve (New World Medical, Inc., Rancho Cucamonga, CA) creates a flow-restriction, and is specifically manufactured for patients with refractory glaucoma; these cases are associated with a high risk of failure when trabeculectomy is carried out, along with a high risk of persistent high intraocular pressure. ${ }^{6-10}$ The size of the Ahmed valve plate placed close to the equator is $184 \mathrm{~mm} .^{211}$

The Ahmed glaucoma valve (AGV), a unidirectional valve, has been shown to be beneficial for the prevention of hypotony and choroidal haemorrhage in the first few weeks after surgery. ${ }^{12,13}$ However, the AGV is known to fail on occasion, primarily due to the formation of blebs around the plate as a direct result of scar formation. Following valve surgery, a large number of patients require glaucoma medications in order to control intraocular pressure (IOP) within normal the normal range. . $^{6,9,14}$

Furthermore, the intraoperative application of mitomycin-c during the implantation of an AGV does not prevent, or inhibit, the formation of scar tissue around the plate. ${ }^{15}$ Previous data also indicate that the surgical implantation of an AGV creates a resistance to aqueous flow, thus reducing the chances of long-term success. ${ }^{16}$ The current consensus of opinion is that bleb-related inflammation and scarring observed after the implantation of an AGV could be related to the biomaterial that is used to construct the Ahmed valve plate. Research has shown that AGVs will induce less inflammation if they are manufactured with silicone plates, rather than polypropylene plates. ${ }^{17,18}$

At present, there are two models of AGV on the market: one with a polypropylene plate (the S2 AGV), and one with a silicone plate (the FP7 AGV). The silicone-based FP7 AGV has the same dimensions, and surface area, as the polypropylene-based S2 AGV, but with a greater degree of flexibility. However, a previous study directly compared these two types of AGV over a oneyear follow-up period and reported that the siliconebased AGV (the FP7) was associated with a greater extent of hypotony. ${ }^{19}$

The objectives of the present study were to investigate the clinical effects associated with the silicone-based AGV and polypropylene-based AGV with regards to the surrounding capsule, and the post-surgical control of IOP.

\section{Methods and Subjects}

This was a prospective and randomized study. The study protocol was approved by the Ethics Committee of Ain Shams University (Registration numbers: FWA 000017585 and FMASU R19/2017) and was also registered as and approved at ClinicalTrials.gov (ID: NCT04214847). The study was carried out in accordance with the tenets of the Declaration of Helsinki, and all participants provided written informed consent to participate.

Patients were included if they had been diagnosed with primary glaucoma and had experienced repeated trabeculectomy failure, or other intraocular surgery. We also included patients diagnosed with secondary glaucoma and associated with high failure trabeculectomy failure rates, such as those with neovascular problems, uveitis, post-keratoplasty glaucoma, or iridocorneal endothelial syndrome-associated glaucoma.

Patients were excluded from the study if they lacked light perception, were unwilling or unable to provide informed consent, if they lived outside of the study area, if they were not available for follow-up visits, or if they had been implanted with an aqueous shunt in the same eye on a prior occasion. Patients were also excluded if there were any other external factors that might restrict superotemporal drainage following device implantation, including the presence of silicone oil, the presence of a sufficient volume of vitreous humor in the anterior chamber, thus necessitating vitrectomy; uveitis associated with a systemic condition, such as juvenile rheumatoid arthritis, nanophthalmos, Sturge-Weber syndrome, or other conditions associated with elevated epi-scleral venous pressure.

\section{Randomization and Treatment}

In this study, our intention was to identify differences in a range of outcome variables following the implantation of S2 and FP7 AGVs, while minimizing other confounding factors, such as surgical experience. To do this, we screened all participants, recruited those who met our specific inclusion criteria, and obtained written and informed consent to participate. Each of the recruited patients was assigned a study number and randomized in accordance with a simple block randomization scheme. Patients were thus randomly assigned to either the S2 group or the FP7 group.

\section{Surgical Procedure}

The same surgical procedure was used to implant both the S2 and FP7 AGVs; this procedure has been described 
previously. ${ }^{9,14}$ All surgical procedures were performed by a single surgeon and were performed under local anaesthesia in all adults; we only used general anaesthesia for children. First, we prepared a fornix-based conjunctival flap, primed the valve plate, and then fitted the plate into the superotemporal quadrant. Prior to implantation, we soaked sponges with $0.3 \mathrm{mg} / \mathrm{mL}$ of mitomycin-c and applied the sponge to the bare sclera of the superotemporal quadrant for 3 mins. The valve plate was secured to the sclera by $10-0$ nylon sutures, placed $10 \mathrm{~mm}$ posterior to the limbus. The tube was placed in the anterior chamber through a tract at the limbus, created by a 23 -gauge needle. The tube was left patent, and a viscoelastic substance was injected into the anterior chamber. A donor scleral graft was then secured by interrupted 10-0 nylon sutures over the exposed portion of the tube; the conjunctiva was then sutured with $10-0$ nylon sutures.

\section{Postoperative Medication and Follow-Up}

The postoperative regimen included the application of a topical antibiotic for 3 to 4 weeks, and topical steroids for approximately 2 months. Antiglaucoma medication was also administered to help maintain the IOP at reduced levels. Sutures were removed 10 days after surgery.

\section{Patients Visits}

Patients were followed-up at 1 month, 3 months, 6 months, 9 months, and 12 months post-surgery. At each follow-up visit, we analyzed a range of variables, including IOP, the number of glaucoma medications taken, log MAR visual acuity, and the incidence of complications.

The primary outcome measure was a surgical success (absolute success), defined as an IOP $\leq 16 \mathrm{~mm} \mathrm{Hg}$ (without medication), and guarded success (a controlled IOP $\leq 16 \mathrm{mmHg}$, but with medication). The procedure was deemed to have failed if the IOP lay outside of the successful range on two consecutive visits $(>16 \mathrm{mmHg}$, despite the use of medication). The procedure was also deemed to have failed if the IOP was $<5 \mathrm{mmHg}$, if the patient lost light perception, or if the patient required a second round of surgery (a cyclo-destructive procedure, the implantation of an additional tube shunt, or the implant needed to be removed). A range of secondary outcomes were also determined, including the number of medications, bleb morphology, hypotony, and choroidal detachment following valve implantation. Snellen VA measurements were converted to log MAR equivalents for data analysis.

\section{Statistical Analysis}

We compared a range of demographic and perioperative data between the FP7 and S2 groups. Continuous and quantitative variables were compared between the two groups by the independent $t$-test or the Mann-Whitney test, as appropriate. Discrete and qualitative variables were analyzed using Pearson's chi-squared test or Fisher's Exact Test.

Comparisons between the two groups with regard to preoperative IOP and the number of medications administered were compared by linear regression, and general linear model (GLM) multivariate analysis. Sub-group analyses also compared the S2 and FP7 participants with regards to neovascular and prior trabeculectomy status; these sub-group analyses also involved GLM multivariate analysis. Kaplan-Meier survival analysis was used alongside the Log-rank test; mean and median survival times were reported with $95 \%$ confidence intervals (CIs). Cox regression analysis was also used to investigate and compare predictors between patients in the S2 and FP7 groups.

We also used a power calculation to predict the sample size required to detect a difference of $4-5 \mathrm{mmHg}$ in mean IOP across the 12 months post-surgery, assuming a standard deviation (SD) of $6 \mathrm{mmHg}$ between the two groups; a previous study reported that IOP was 4-5-mmHg lower with a silicone-based valve than a polypropylene-based card. $^{20,26}$ The power of our study to detect a $20 \%$ difference between the two groups was determined to be 0.8 . A $P$ value $<0.05$ was considered to be statistically significant.

\section{Results}

Patients were recruited and randomly assigned to S2 and FP7 groups. Randomization assigned 28 patients (27 adults, and an 8-year-old child) to the $\mathrm{S} 2$ group, and 28 patients (27 adults, and a 7-year-old child) to the FP7 group. A total of 56 patients were, therefore, enrolled in the study between 2012 and 2014. The median age was 51.00 years, and the interquartile range was 8.75 years. In the $\mathrm{S} 2$ group, the median age was 53.00 and the interquartile range was 7.00 years. In the FP7 group, the median age was 49.00 and the interquartile range was 8.75 years.

When considering adults only (54 participants), the median age of the entire study cohort was 51.50 years, and the interquartile range was 8.00 years. In the $\mathrm{S} 2$ group, the median age was 53.00 years, and the interquartile range was 7.00; in the FP7 group, the median age was 51.00 years, and the interquartile range was 9.00 years. In 
the S2 group, 13 patients were female and 15 were male; this compared to 10 females and 18 males in the FP7 group. The mean follow-up period was $398.42 \pm 12.34$ days (range, 380-420 days) in theS2 group, and $401.75 \pm$ 9.78 days (range, $385-420$ days) in the FP7 group; there was no significant difference between the two groups with this respect $(\mathrm{P}=0.27)$.

Baseline demographic and ocular characteristics were similar when compared between the S2 and FP7 groups (Table 1). There were no significant differences in terms of

Table I Demographic Data of the 56 Participants, and Adult Groups, Assigned to the S2 and FP7 Groups

\begin{tabular}{|c|c|c|c|}
\hline Demographic Data of Patients & $\begin{array}{l}\text { Ahmed Valve Surgery Polypropylene } \\
\text { Valve(S2) (28) }\end{array}$ & $\begin{array}{l}\text { Ahmed Valve Surgery Silicone Valve } \\
\text { (FP7) (28) }\end{array}$ & $P$ value \\
\hline $\begin{array}{l}\text { Median age in years } \\
\text { Interquartile Range in adult group }\end{array}$ & $\begin{array}{l}53.00 \\
7.00\end{array}$ & $\begin{array}{l}49.00 \\
8.75\end{array}$ & $0.099 * * *$ \\
\hline $\begin{array}{l}\text { Median age in years } \\
\text { Interquartile Range in adult group }\end{array}$ & $\begin{array}{l}53.00 \\
7.00\end{array}$ & $\begin{array}{l}51.00 \\
9.00\end{array}$ & $0.179 * * *$ \\
\hline $\begin{array}{l}\text { Sex } \\
\text { Female } \\
\text { Male }\end{array}$ & $\begin{array}{l}13 \\
15\end{array}$ & $\begin{array}{l}10 \\
18\end{array}$ & $0.415^{* *}$ \\
\hline $\begin{array}{l}\text { Glaucoma subtypes } \\
\text { Neovascular glaucoma } \\
\text { Glaucoma with prior trabeculectomy } \\
\text { procedure } \\
\text { I-Uveitic glaucoma } \\
\text { 2-Congenital glaucoma } \\
\text { 3-Primary open angle glaucoma } \\
\text { 4-Pseudophakic glaucoma } \\
\text { Postkeratoplasty glaucoma }\end{array}$ & $\begin{array}{l}10(35.71 \%) \\
17(60.71 \%) \\
4 \\
2 \\
10 \\
1 \\
1(3.57 \%)\end{array}$ & $\begin{array}{l}12(42.85 \%) \\
15(53.57 \%) \\
2 \\
2 \\
8 \\
3 \\
1(3.57 \%)\end{array}$ & $0.857^{* *}$ \\
\hline $\begin{array}{l}\text { Previous ocular surgery } \\
\text { Trabeculectomy } \\
\text { Penetrating keratoplasty } \\
\text { Cataract extraction } \pm \text { intraocular lens } \\
\text { placement }\end{array}$ & $\begin{array}{l}\text { I8 }(1 \text { ) surgeries in ten patients } \\
7 \text { Trabeculectomies in secondary and } \\
\text { congenital glaucoma } \\
\text { I(3.57\%) } \\
2 \mathrm{I}(75 \%)\end{array}$ & $\begin{array}{l}16 \text { (9 surgeries in eight patients) } \\
7 \text { Trabeculectomies in secondary and } \\
\text { congenital glaucoma } \\
I(3.57 \%) \\
23(82 \%)\end{array}$ & $0.900 * *$ \\
\hline $\begin{array}{l}\text { Other procedures } \\
\text { Panretinal photocoagulation } \\
\text { ranibizumab injection } \\
\text { Diode laser cycloablation }\end{array}$ & $\begin{array}{l}10 \text { cases }(35 \%) \\
20 \text { injections } \\
\mathrm{I}(3.57 \%)\end{array}$ & $\begin{array}{l}8 \text { cases }(28 \%) \\
30 \text { injections } \\
I(3.57 \%)\end{array}$ & $0.515^{* *}$ \\
\hline $\begin{array}{l}\text { Preoperative IOP in } 56 \text { participants } \\
\text { Preoperative IOP in adult group }\end{array}$ & $\begin{array}{l}45.42 \mathrm{mmHg} \pm 6.39 \\
45.33 \mathrm{mmHg} \pm 6.49\end{array}$ & $\begin{array}{l}44.17 \mathrm{mmHg} \pm 5.98 \\
43.92 \mathrm{mmHg} \pm 5.94\end{array}$ & $\begin{array}{l}0.453^{*} \\
0.410^{*}\end{array}$ \\
\hline $\begin{array}{l}\text { Visual acuity }(2 / 60-6 / 24) \\
\text { Median } \\
\text { Interquartile Range }\end{array}$ & $\begin{array}{l}1.07 \\
0.18\end{array}$ & $\begin{array}{l}1.03 \\
0.40\end{array}$ & $0.778 * * *$ \\
\hline $\begin{array}{l}\text { PSD before surgery } \\
\text { Median } \\
\text { Interquartile Range }\end{array}$ & $\begin{array}{l}5.30 \\
2.85\end{array}$ & $\begin{array}{l}6.00 \\
2.10\end{array}$ & $0.623 * * *$ \\
\hline $\begin{array}{l}\text { Number of glaucoma medication in } 56 \\
\text { participants } \\
\text { Number of glaucoma medication in } \\
\text { adult group }\end{array}$ & $\begin{array}{l}3.93 \pm 0.26 \\
3.92 \pm 0.26\end{array}$ & $\begin{array}{l}3.89 \pm 0.31 \\
3.88 \pm 0.31\end{array}$ & $\begin{array}{l}0.647^{* *} \\
0.639 * *\end{array}$ \\
\hline
\end{tabular}

Notes: *Assessed by an independent $t$-test, ${ }^{* *}$ Assessed by the chi-squared test of independence $\left(X^{2}\right),{ }^{* * *}$ Assessed by the Mann-Whitney test. 
glaucoma diagnoses when compared between the two groups; of the entire cohort, $39 \%$ of patients received a diagnosis of neovascular glaucoma, $57 \%$ with glaucoma associated with a previous trabeculectomy procedure, and $4 \%$ with post-keratoplasty glaucoma. Previous surgeries included trabeculectomy with mitomycin-c, repeat trabeculectomies, cataract surgeries, and penetrating keratoplasty (PKP); overall, $78 \%$ of patients experienced phaco surgery, 57\% experienced trabeculectomies with mitomycin-c, and $4 \%$ experienced penetrating keratoplasty. In addition, $32 \%$ of patients experienced pan-retinal photocoagulation and repeated ranibizumab injection prior to surgery; $4 \%$ of patients experienced diode laser cycloablation prior to surgery (Table 1).

Figures 1 and 2 show the mean IOPs over a one-year follow-up period for the 56 participants and the adult groups.

The means of IOP ,SD represented with error bar, P-values of S2 and FP7 participants in 56 participants group

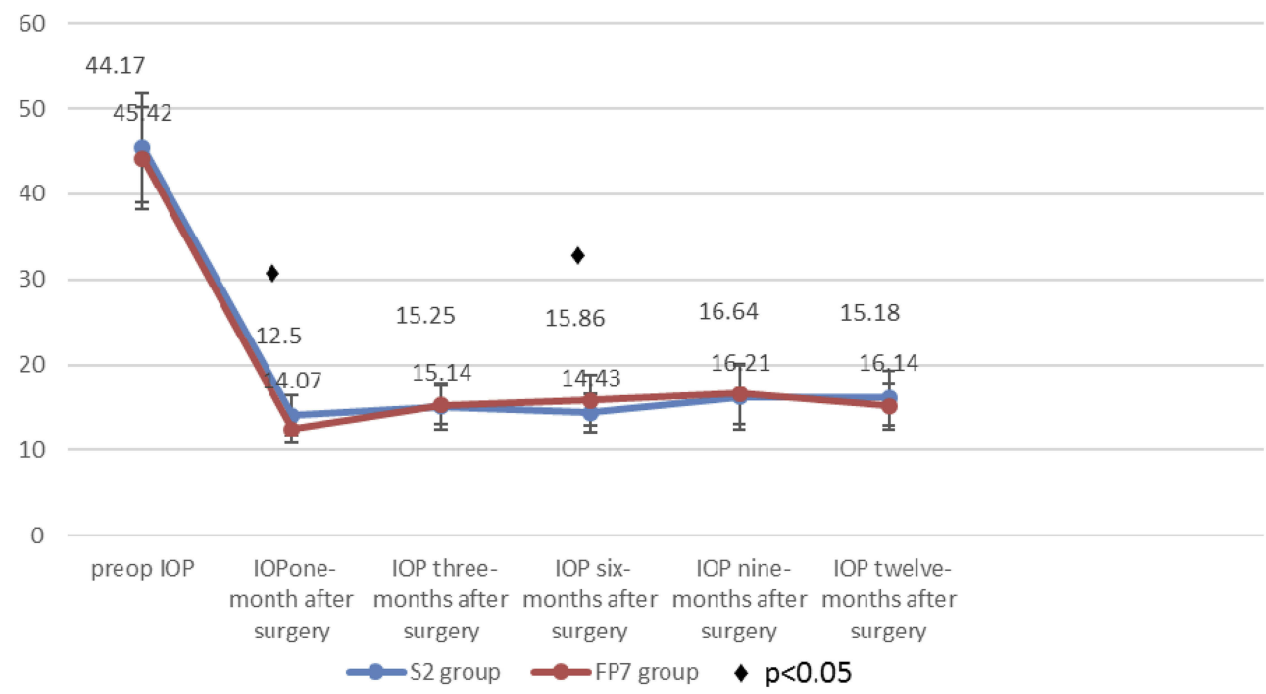

Figure I Mean ( \pm SD) IOP for the 56 participants in the S2 and FP7 groups. $\mathrm{P}=0.005$ and $\mathrm{P}=0.044$ at $\mathrm{I}$ - and 6 -month post-surgery, respectively. The mean preoperative IOP fell from $45.42 \pm 6.93 \mathrm{mmHg}$ and $44.17 \pm 5.98 \mathrm{mmHg}$ before surgery to $16.14 \pm 3.18 \mathrm{mmHg}$ and I $18.18 \pm 2.75 \mathrm{mmHg}$ at the one-year follow-up, in the S2 and FP7 groups, respectively $(P=0.23)$.

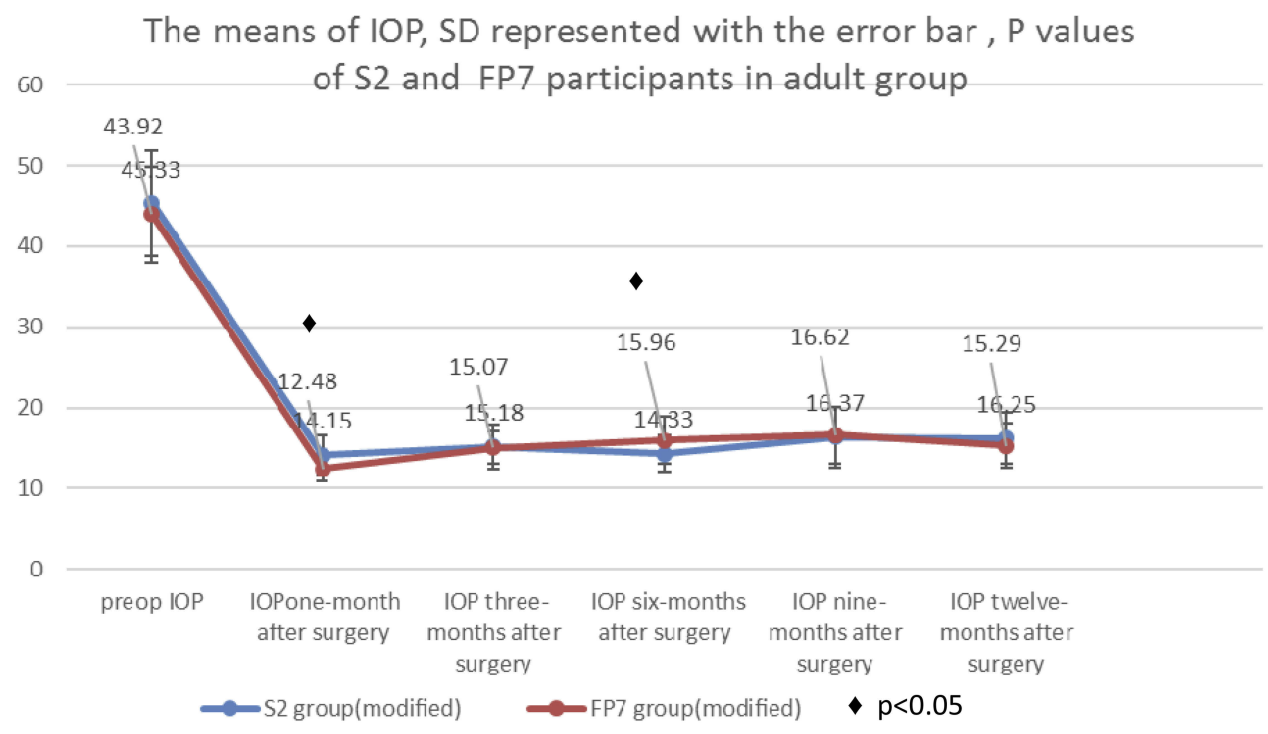

Figure 2 Mean $( \pm S D)$ IOP in the adults assigned to the S2 and FP7 groups. $\mathrm{P}=0.004$ and 0.024 at I- and 6-month post-surgery. The mean preoperative IOP fell from 45.33 $\pm 6.49 \mathrm{mmHg}$ and $43.92 \pm 5.94 \mathrm{mmHg}$ before surgery to $16.25 \pm 3.18 \mathrm{mmHg}$ and I $5.29 \pm 2.72 \mathrm{mmHg}$ at the one-year follow-up, in the $\mathrm{S} 2$ and FP7 groups, respectively $(\mathrm{P}=$ $0.24)$. 
The mean preoperative IOPs did not differ significantly when compared between the S2 and FP7 groups $(\mathrm{P}=0.45$ and $\mathrm{P}=0.41$, respectively). For both groups, the postoperative mean IOPs, at $1,3,6,9$, and 12 months, were significantly lower than the baseline IOP $(\mathrm{P}=0.000$ and $\mathrm{P}=$ 0.000 , respectively). When considering the 56 participants and adult groups, there was a significant difference between the $\mathrm{S} 2$ and FP7 groups in terms of mean IOP at 1 month $(\mathrm{P}=$ 0.005 and $\mathrm{P}=0.004)$ and 6 months $(\mathrm{P}=0.005$ and $\mathrm{P}=$ 0.004) post-surgery, but no significant difference at any other follow-up timepoints. In the two pediatric patients, preoperative IOP decreased significantly in both the S2 and FP7 groups over the one-year follow-up period, falling from 48 and $51 \mathrm{mmHg}$ to 13 and $12 \mathrm{mmHg}$, respectively.

Figures 3 and 4 show the mean number of glaucoma medications required by 56 participants, and the adult groups, at the one-year follow-up timepoint. Patients in the S2 group began to use glaucoma medication 30 days post-surgery, while patients in the FP7 group began to use glaucoma medication 90 days post-surgery. There were no significant differences between the two groups at any of the follow-up timepoints with regard to the mean number of anti-glaucoma medications required, except for the first month $(\mathrm{P}=0.000, \mathrm{P}=0.000)$, and the ninth month ( $\mathrm{P}=0.005,56$ participants; Table 2$)$.

Glaucoma medication was administered to the S2 and FP7 groups in order to control the mean IOP. At the final follow-up, there was only a small difference between the S2 and FP7 groups with regard to glaucoma medication. However, there was a significant difference between preoperative medication and postoperative medication at the one-year follow-up $(\mathrm{P}=0.000)$.

The final follow-up data for the 56 participants, and the adult groups, are shown in Table 2. At the final follow-up, the mean IOPs were $16.14 \mathrm{mmHg}$ and $16.25 \mathrm{mmHg}$ in the $\mathrm{S} 2$ group, and $15.18 \mathrm{mmHg}$ and $15.29 \mathrm{mmHg}$ in the FP7 group $(\mathrm{P}=0.23, \mathrm{P}=0.24)$, while the mean number of medications was 2.92 and 2.96 in the $\mathrm{S} 2$ group, and 2.75 and 2.70 in the FP7 group $(\mathrm{P}=0.32, \mathrm{P}=0.26)$.

At the final follow-up visit, the VA was stable in most patients (for both groups), although we observed a worsening VA in 3 patients (10.7\%) of the FP7 group, and in 5 patients $(17.8 \%)$ of the S2 group. None of the patients lost their perception to light.

Kaplan-Meier analysis showed that the rates of surgical success at 12 months were $89 \%$ and $82 \%$ for the FP7 group and the $\mathrm{S} 2$ group, respectively ( $\mathrm{P}=0.41$; Figure 5 ). Mean survival times for the FP7and S2 groups were 402.54 days (95\% CI, 396.70-408.37 days) and 394.76 days (95\% CI, $381.23-408.28$ days), respectively. Absolute success at oneyear follow-up was achieved in $5 / 28$ patients $(17.8 \%)$ in the FP7 group, and $3 / 28$ patients $(10.7 \%)$ in the $\mathrm{S} 2$ group $(\mathrm{P}=$ 0.38 ). Guarded success at one-year follow-up was achieved in $18 / 28$ patients $(64.28 \%)$ in the FP7 group, and 19/28

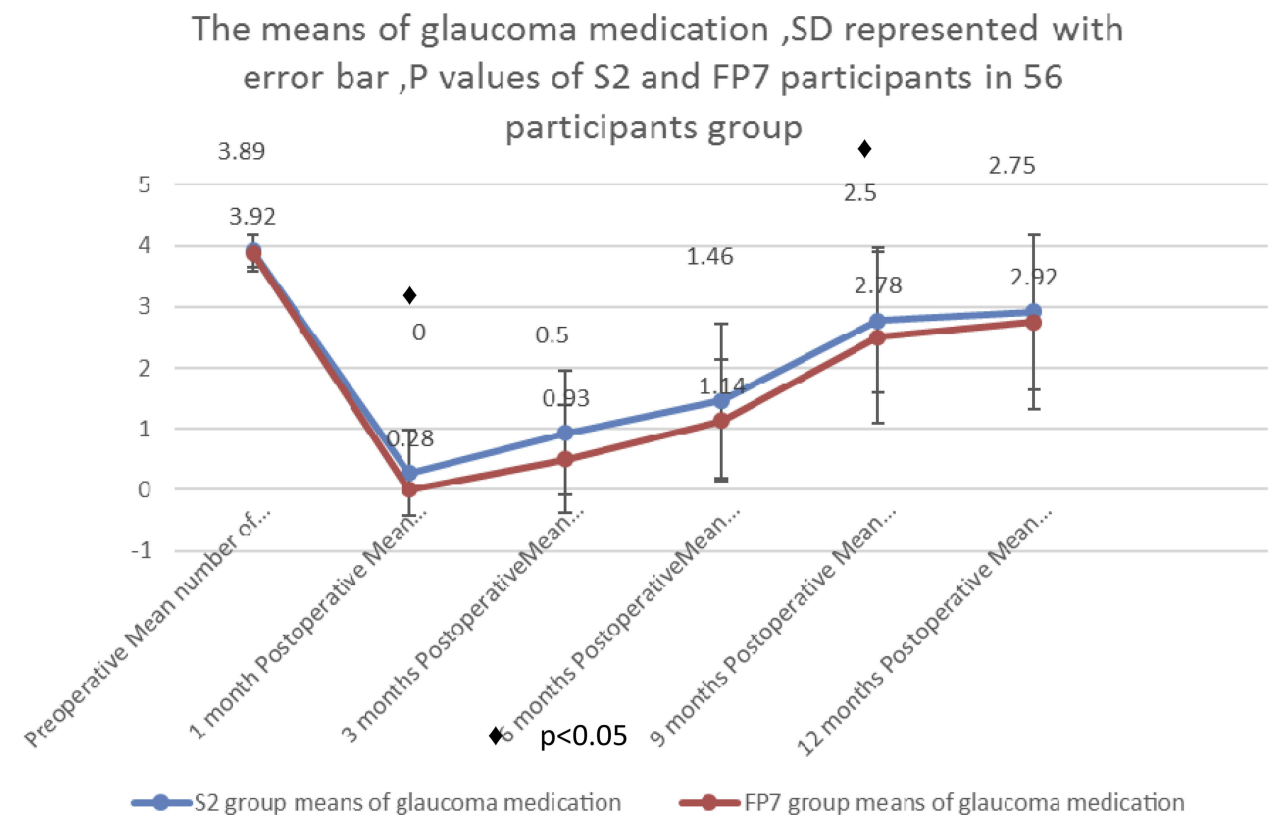

Figure 3 Mean number $( \pm S D)$ of glaucoma medications administered in the 56 participants in the $S 2$ and Fp7 groups. $\mathrm{P}=0.000$ and $\mathrm{p}=0.005$ at $\mathrm{I}-$ and 9 -month postsurgery. The mean number of medications administered fell from $3.92 \pm 0.26$ and $3.89 \pm 0.31$ before surgery to $2.92 \pm 1.27$ and $2.75 \pm 1.43$ at the one-year follow-up, in the $S 2$ and FP7 groups, respectively $(P=0.316)$. 


\section{The means of glaucoma medication ,SD represented with} error bar,P values of S2 and FP7 participants in adult group

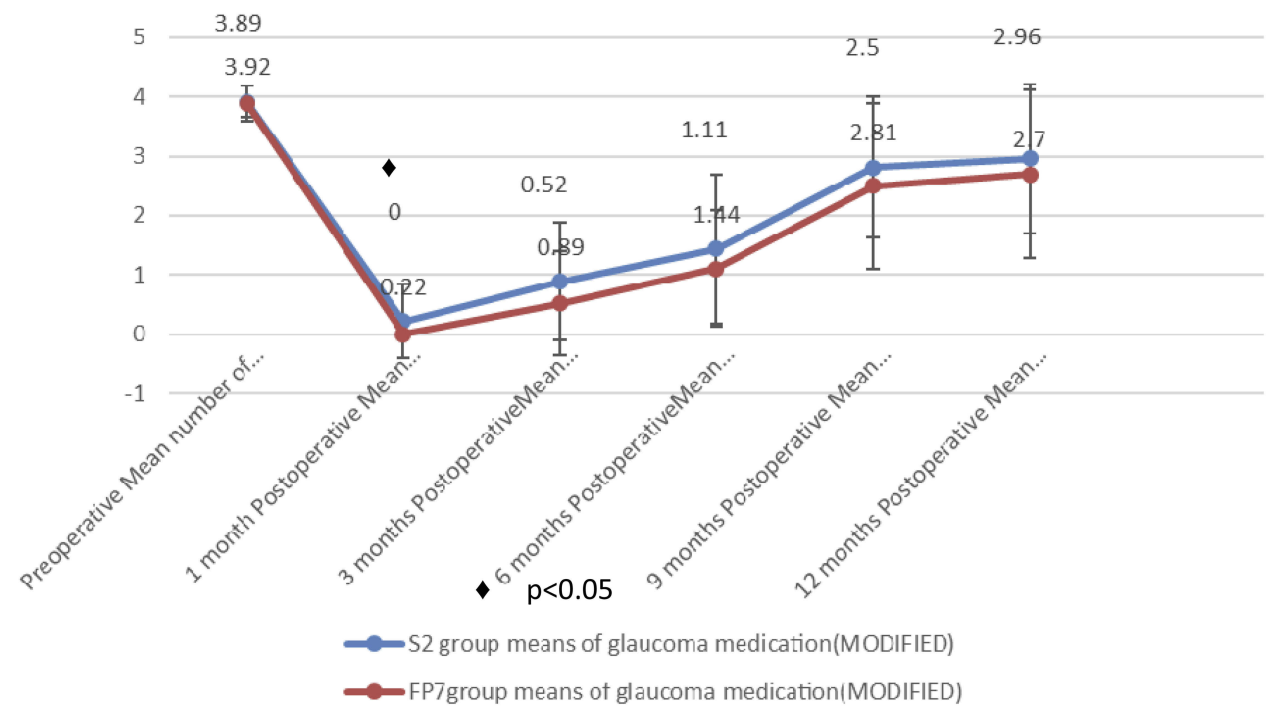

Figure 4 Mean number $( \pm S D)$ of glaucoma medications administered in the adult cohort of the $S 2$ and Fp7 groups. $P=0.000$ at I month after surgery. The mean number of medications administered fell from $3.92 \pm 0.26$ and $3.89 \pm 0.3 \mathrm{I}$ before surgery to $2.96 \pm 1.26$ and $2.7 \pm \mathrm{I} .4 \mathrm{I}$, at the one-year follow-up, in the S2 and FP7 groups, respectively $(P=0.256)$.

patients $(67.85 \%)$ in the $\mathrm{S} 2$ group $(\mathrm{P}=0.25)$. Treatment was deemed to have failed in $5 / 28$ patients $(17.8 \%)$ in the FP7 group, and 6/28 patients $(21.42 \%)$ in the $\mathrm{S} 2$ group $(\mathrm{P}=$ $0.07)$, when evaluated at one-year follow-up. There were no significant differences between the FP7 group and the S2 group with regards to complete surgical success, qualified surgical success, and surgical failure.

Multivariate sub-group analysis revealed that patients in the S2 group who had experienced previous trabeculectomy had a significantly lower IOP when compared with the sub-group who had experienced neovascular glaucoma $(\mathrm{P}=0.03)$. In the FP7 group, there was no significant difference in mean IOP when compared between the neovascular group of patients, and the group of patients who had experienced previous trabeculectomy subgroups $(\mathrm{P}=$ 0.57). Consequently, neovascular glaucoma should be considered as a risk factor for failure in the S2 group of patients. There were no statistical differences identified with regards to previous trabeculectomy status, neovascular glaucoma, or implant type $(\mathrm{P}=0.91, \mathrm{P}=0.12)$.

\section{Visual Acuity}

Prior to surgery, the corrected visual acuity of the entire study cohort varied between $2 / 60$ and $6 / 24$ in the S2 and FP7 groups (Table 1). In the S2 group, two cases showed a 5-letter improvement (7.1\%), five cases showed a 5-letter deterioration (17.8\%), and 21 cases retained stable visual acuity (75\%). In the FP7 group, three cases showed a 5-letter improvement (10.7\%), three cases showed a 5-letter deterioration (10.7\%), and 22 cases (78.5\%) retained stable visual acuity. There were no significant differences in terms of visual acuity when compared between baseline and one-year follow-up in the S2 and FP7 groups $(\mathrm{P}=0.65, \mathrm{P}=0.69$; Figure 6).

\section{Visual Fields}

Twenty eyes (35.5\%) had a reliable visual field when evaluated both before and after surgery. For comparison, 12 cases had a concentric contraction of the visual field with a nasal step, four cases had a tubular field, and another four cases had a tubular field with the splitting of the fixation area. Twelve cases had localized defects, with a high mean deviation (MD; range: $-10 \mathrm{~dB}-16 \mathrm{~dB}$ ), and a high pattern standard deviation (PSD; range: 4-8 dB). Eight cases had marked generalized depression, with a high MD (range: -14-26 dB) and a low PSD (range: $3-5 \mathrm{~dB}$ ). Statistical analysis detected no real progression in 12 cases $(\mathrm{P}=0.95)$ Four cases in the S2 group, and four cases in the FP7 group, had localized defects, and an increase in density, with PSD values ranging from $4.2 \mathrm{~dB}$ to $8.1 \mathrm{~dB}$. There were no significant differences in terms of PSD when compared before surgery and at a one-year follow-up $(\mathrm{P}=0.65-\mathrm{P}=$ 0.69); this was the case for both the S2 and the FP7 group. 
Table 2 Intraocular Pressure and Medical Therapy at Baseline and One-Year Follow-Up in 56 Participants, and the Adult Groups

\begin{tabular}{|c|c|c|c|}
\hline $\begin{array}{l}\text { IOP (mmHg; mean } \pm \text { SD) ( } 95 \% \text { Confidence Interval) } \\
\text { Glaucoma Medication }\end{array}$ & S2 Group, n (\%) & FP7 Group, n (\%) & $P$ value \\
\hline IOP (mmHg; mean \pm SD) & $45.42 \mathrm{mmHg} \pm 6.39$ & $44.17 \mathrm{mmHg} \pm 5.98$ & $0.45^{*}$ \\
\hline Preoperative IOP in 56 participants & $(42.95-47.90)$ & $(41.86-46.50)$ & \\
\hline Preoperative IOP in adult group & $\begin{array}{l}45.33 \mathrm{mmHg} \pm 6.49 \\
(43.53-48.17)\end{array}$ & $\begin{array}{l}43.92 \mathrm{mmHg} \pm 5.94 \\
(41.42-46.07)\end{array}$ & $0.4 I^{*}$ \\
\hline Glaucoma medication in 56 participants & $3.93 \pm 0.26$ & $3.89 \pm 0.31$ & $0.07 * *$ \\
\hline Glaucoma medication in adult group & $3.92 \pm 0.26$ & $3.88 \pm 0.31$ & $0.6 I^{* *}$ \\
\hline One- month Postoperative & $14.07 \mathrm{mmHg} \pm 2.35$ & $12.50 \mathrm{mmHg} \pm 1.62$ & $0.005^{*}$ \\
\hline IOP in 56 participants & $(13.60-14.99)$ & $(11.87-13.13)$ & \\
\hline One- month Postoperative & $14.15 \mathrm{mmHg} \pm 2.36$ & $12.48 \mathrm{mmHg} \pm 1.64$ & $0.004 *$ \\
\hline IOP in adult group & $(13.30-14.83)$ & $(11.73-13.26)$ & \\
\hline Glaucoma medication in 56 participants & $0.28 \pm 0.71$ & 00 & $0.000^{\star}$ \\
\hline Glaucoma medications in adult group & $0.26 \pm 0.62$ & 00 & $0.000^{\star}$ \\
\hline Three months Postoperative & $15.14 \mathrm{mmHg} \pm 2.69$ & $15.25 \mathrm{mmHg} \pm 2.24$ & $0.87^{*}$ \\
\hline IOP in 56 participants & $(14.10-16.18)$ & $(14.38-16.12)$ & \\
\hline Three months Postoperative & $15.18 \mathrm{mmHg} \pm 2.73$ & $15.07 \mathrm{mmHg} \pm 2.07$ & $0.87^{*}$ \\
\hline IOP in adult group & $(14.20-16.08)$ & $(14.3 \mid-16.18)$ & \\
\hline Glaucoma medications in 56 participants & $0.93 \pm 1.02$ & $0.5 \pm 0.88$ & $0.67 * *$ \\
\hline Glaucoma medications in in adult group & $0.88 \pm 0.99$ & $0.5 I \pm 0.87$ & $0.92 * *$ \\
\hline Six months Postoperative & $14.43 \mathrm{mmHg} \pm 2.23$ & $15.86 \mathrm{mmHg} \pm 2.90$ & $0.04 *$ \\
\hline IOP in 56 participants & $(13.56-15.29)$ & $(14.73-16.98)$ & \\
\hline Six months Postoperative & $14.33 \mathrm{mmHg} \pm 2.22$ & $15.96 \mathrm{mmHg} \pm 2.90$ & $0.02 *$ \\
\hline IOP in adult group & $(13.44-15.4 \mid)$ & $(14.87-16.83)$ & \\
\hline Glaucoma medications in 56 participants & $1.46 \pm 1.26$ & $1.14 \pm 1.00$ & $0.09 * *$ \\
\hline Glaucoma medications in adult group & $1.44 \pm 1.25$ & $1.11 \pm 0.99$ & $0.11 * *$ \\
\hline Nine months Postoperative & $16.21 \mathrm{mmHg} \pm 3.74$ & $16.64 \mathrm{mmHg} \pm 3.50$ & $0.66^{*}$ \\
\hline IOP in 56 participants & $(14.76-17.66)$ & $(15.28-17.99)$ & \\
\hline Nine months Postoperative & $16.37 \mathrm{mmHg} \pm 3.72$ & $16.62 \mathrm{mmHg} \pm 3.56$ & $0.79 *$ \\
\hline IOP in adult group & $(14.84-17.58)$ & $(15.27-18.01)$ & \\
\hline Glaucoma medications in 56 participants & $2.78 \pm 1.19$ & $2.50 \pm 1.40$ & $0.005 * *$ \\
\hline Glaucoma medications in adult group & $2.81 \pm 1.18$ & $2.51 \pm 1.39$ & $0.86 * *$ \\
\hline Twelve months & $16.14 \mathrm{mmHg} \pm 3.18$ & $15.18 \mathrm{mmHg} \pm 2.75$ & $0.23^{*}$ \\
\hline Postoperative IOP in 56 participants & $(14.90-17.37)$ & $(14.11-16.24)$ & \\
\hline Twelve months & $16.25 \mathrm{mmHg} \pm 3.18$ & $15.29 \mathrm{mmHg} \pm 2.72$ & $0.24 *$ \\
\hline Postoperative IOP in adult group & $(15.01-17.27)$ & $(14.05-16.30)$ & \\
\hline Glaucoma medications in 56 participants & $2.92 \pm 1.27$ & $2.75 \pm 1.43$ & $0.32^{* *}$ \\
\hline Glaucoma medications in adult group & $2.96 \pm 1.26$ & $2.70 \pm 1.40$ & $0.26 * *$ \\
\hline
\end{tabular}

Notes: *Assessed by an independent $t$-test, **Assessed by the chi-squared test of independence $\left(\mathrm{X}^{2}\right)$, Assessed by Wilcoxon Signed Ranks Test.

\section{Surgical Complications}

A range of post-operative complications were observed. For example, early reversible choroidal detachment was recorded in 12 cases in $42.8 \%$ of the FP7 group. Early, and transient hypotony, defined as an IOP $<5 \mathrm{mmHg}$, was detected in 5 eyes (17.8\% of the FP7 group). Mild to moderate hyphemia was seen in 8 eyes ( 5 eyes in the FP7 group, $17.8 \%$; 3 eyes in the S2 group, 10.7\%). Six eyes had tube exposure (4 eyes in the FP7 group, 14.2\%; 2 eyes in the S2 group, 7.1\%). Late corneal oedema developed after surgery in two eyes (both in the S2 group, $7.1 \%$ ). Dellen formation was detected in a single case from the FP7 group; this patient received a corneal graft. In the $\mathrm{S} 2$ group, the conjunctival bleb above the plate was flattened, greyish white; the plate border could be delineated in eight eyes (28.5\%). In the FP7 group, the 


\section{Survival Functions OF S2 and FP7 curves}

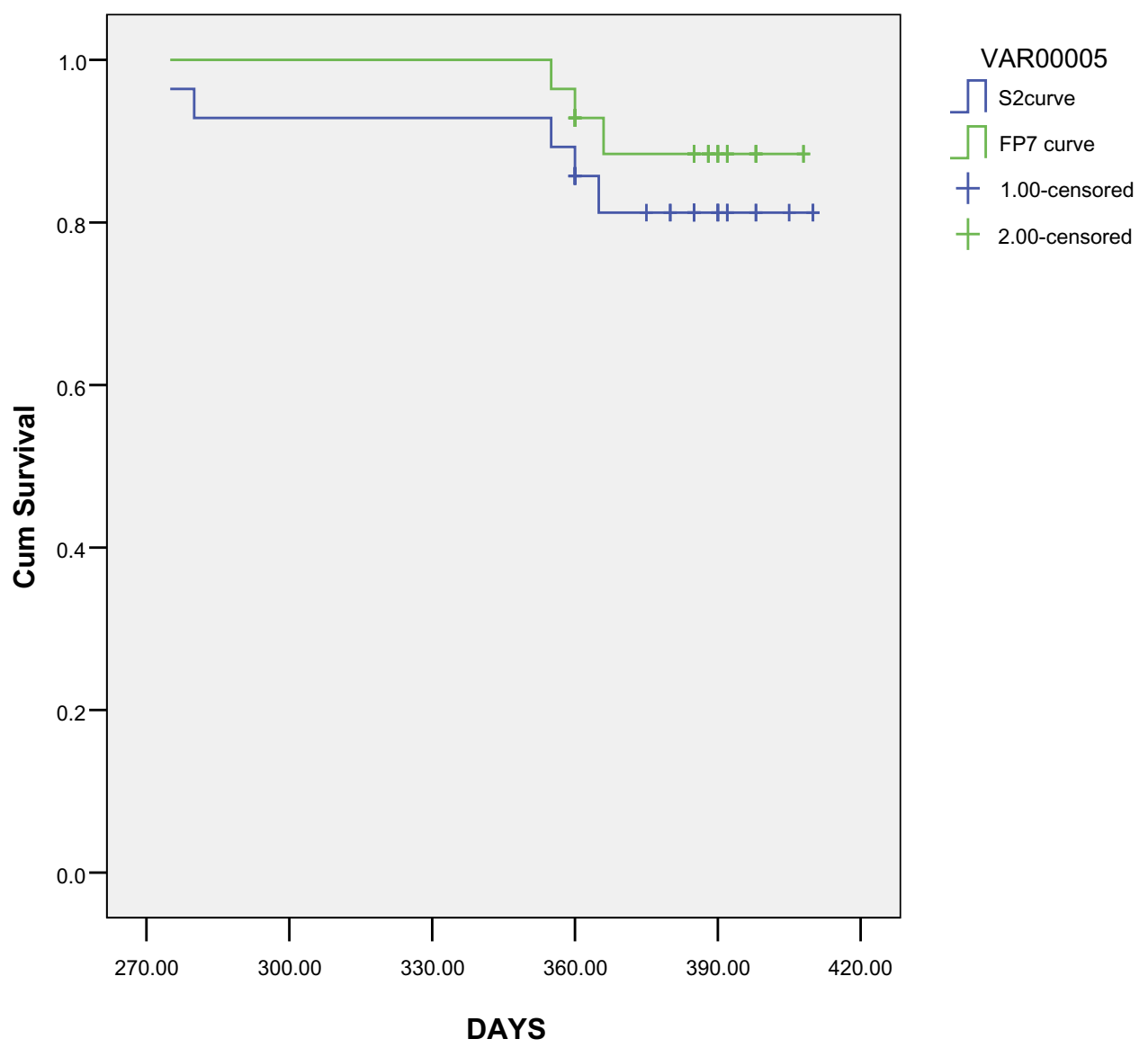

Figure 5 Survival curves for the S2 (blue line) and FP7 (green line) groups. Success rates were $89 \%$ and $82 \%$ at 12 months for the FP7 group and the S2 group, respectively. The S2 curve began to fail at approximately 270 days. Mean survival times for the S2 group and FP7 group were 394.76 days ( $95 \%$ Cl, 38I.23-408.28) and 402.54 days ( $95 \%$ $\mathrm{Cl}, 396.70-408.37)$, respectively. The differences between the S2 and FP7 curves for the 2 groups were not statistically significant (0.4I4).

conjunctival bleb above the plate was flattened, greyish white, and was detected in two eyes $(7.1 \%)$.

Finally, we used a Cox proportional hazard regression models to identify statistical associations between various variables and clinical outcome measures (Table 3). Our analysis showed that postoperative hypotony, postoperative choroidal detachment, hyphemia, tube exposure, and bleb morphology did not show a positive association with clinical outcome.

\section{Discussion}

In the present study, we found that IOP decreased significantly from $45.42 \pm 6.39 \mathrm{mmHg}$ and $44.17 \pm 5.98 \mathrm{mmHg}$ in the S2 and FP7 groups at baseline to $16.14 \pm 3.18 \mathrm{mmHg}$ and $15.18 \pm 2.75 \mathrm{mmHg}$ at the one-year follow-up visit $(\mathrm{P}=$ 0.000). The previous Tube Versus Trabeculectomy Study (TVT), published in 2004, reported that a tube group showed a significant reduction in IOP from $25.1 \pm 5.3$ $\mathrm{mmHg}$ at baseline, to $12.4 \pm 3.9 \mathrm{mmHg}$ at the one-year follow-up visit $(\mathrm{P}=0.000)$; in a trabeculectomy group, IOP fell significantly from $25.6 \pm 5.3 \mathrm{mmHg}$ at baseline, to 12.7 $\pm 5.8 \mathrm{mmHg}$ at the one-year follow-up visit $(\mathrm{P}=0.000){ }^{21}$

In the present study, we found no clinical differences when considering mean IOP, success rate, and the rate of complications, when comparing groups of patients implanted with S2 and FP7 AGVs. Both of these AGVs have similar dimensions but are manufactured using differing materials. Multivariate analysis of the S2 and FP7 groups showed that there were no significant differences in terms of clinical outcomes at the one-year follow-up visit.

Our results also showed that IOP elevation, and the administration of glaucoma medication, occurred earlier in the S2 group than in the FP7 group. This was related to the fact that the FP7 plate presents a smooth surface to the 


\section{Log MAR visual acuity before and after surgery in S2 and FP7 groups}

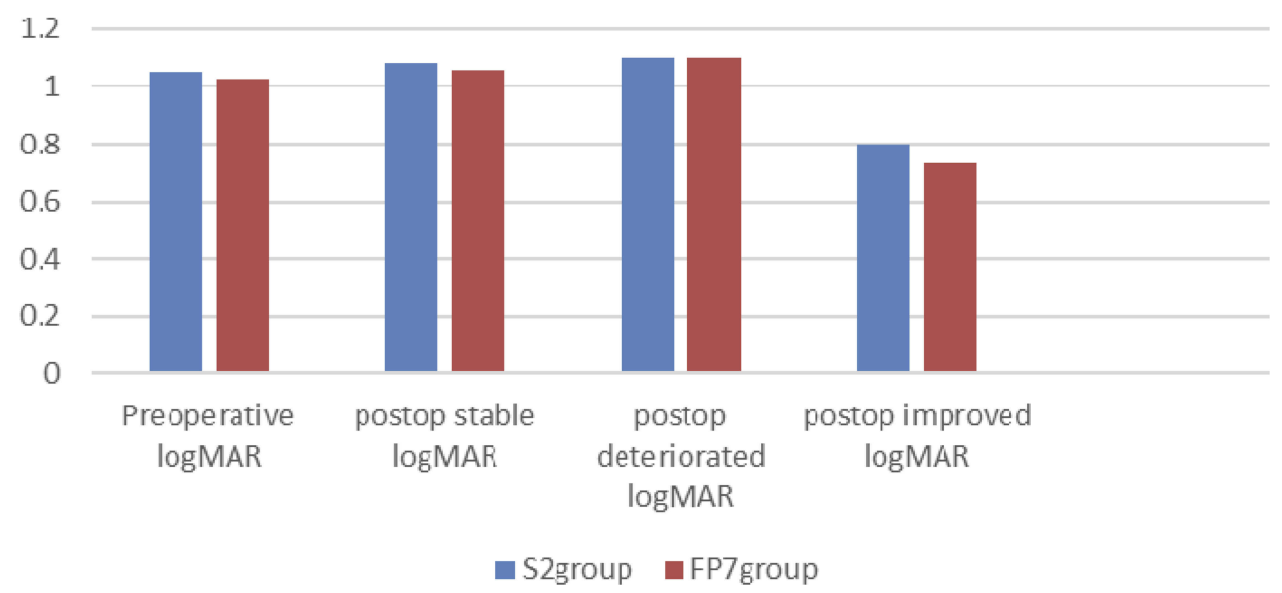

Figure 6 Comparison of log MAR visual acuity before and after surgery involving stable log MAR ( 2 I versus 22 participants), improved log MAR ( 2 versus 3 participants), and deteriorated log MAR (5 versus 3 participants), in the S2 and FP7 groups at the one-year follow-up $(P=0.653$ and $P=0.691)$.

conjunctiva; this is unlike the S2 plate that presents a rough surface to the conjunctiva. The rough polypropylene material may add to the pro-inflammatory response and thus increase the micromotion of platelets. ${ }^{22,23}$ The silicone material contained within the FP7 implants is not

Table 3 Outcomes and Post-Operative Complications in the S2 and FP7 Groups

\begin{tabular}{|l|l|l|l|}
\hline Outcome Variables & $\begin{array}{l}\text { S2 Group, } \\
\mathbf{n}(\%)\end{array}$ & $\begin{array}{l}\text { FP7 Group, } \\
\mathbf{n}(\%)\end{array}$ & P value \\
\hline $\begin{array}{l}\text { Visual Acuity After } \\
\text { Surgery } \\
\text { Median } \\
\text { Interquartile Range }\end{array}$ & $\begin{array}{l}1.079 \\
0.34\end{array}$ & $\begin{array}{l}1.000 \\
0.40\end{array}$ & $0.52 *$ \\
\hline $\begin{array}{l}\text { PSD After Surgery } \\
\text { Median } \\
\text { Interquartile Range }\end{array}$ & $\begin{array}{l}5.3000 \\
2.85\end{array}$ & $\begin{array}{l}6.0000 \\
2.10\end{array}$ & $0.57^{*}$ \\
\hline $\begin{array}{l}\text { Postoperative choroidal } \\
\text { detachment }\end{array}$ & $\begin{array}{l}0.00 \\
\operatorname{Exp}(B) 2.242\end{array}$ & 12 cases & $0.38^{* *}$ \\
\hline Postoperative hypotony & $\begin{array}{l}0.00 \\
\operatorname{Exp}(B) 1.95\end{array}$ & 5 cases & $0.56^{* *}$ \\
\hline Postoperative hyphema & $\begin{array}{l}3 \text { cases } \\
\operatorname{Exp}(B) 1.15\end{array}$ & 5 cases & $0.87^{* *}$ \\
\hline Bleb morphology & $\begin{array}{l}8 \text { cases } \\
\operatorname{Exp}(B) 4.84\end{array}$ & 2 cases & $0.18^{* *}$ \\
\hline Tube exposure & $\begin{array}{l}\text { Exp(B) I.42 } \\
\text { cases }\end{array}$ & 4 cases & $0.74^{* *}$ \\
\hline
\end{tabular}

Notes: *Assessed by the Mann-Whitney test, **Assessed by Cox regression analysis. sufficiently inert to prevent the formation of cysts; ${ }^{13}$ thus, the administration of glaucoma medication began 3 months after surgery in the FP7 group. These results cannot support the concept that the use of different construction materials can provide a solution for progressive capsular scarring and bleb failure. ${ }^{16}$ When constructed with different materials, AGVs exhibit differing degrees of post-operative inflammation and pseudo-capsule formation; ultimately, this may result in scarring around the plate and bleb failure. ${ }^{17,18,24,25}$ The late elevation of IOP, particularly in cases where the intraocular portion of the tube appears to be patent, is usually reflected by an excessively thick fibrous capsule. ${ }^{26}$ Our present data demonstrate a high incidence of significant bleb scarring within the first year of AGV implantation, along with encapsulation of the valve (bleb failure). However, despite this, previous studies have found that patients treated with silicone valves had significantly lower failure rates, along with higher rates of hypotony, endophthalmitis, wound leak, and supra-choroidal hemorrhage. ${ }^{27}$ The size of the drainage plate is another important factor to consider; for the S2 and FP7 models, the size of this plate is $184 \mathrm{~mm}^{2}$. Several studies have shown that the mean IOP can be lowered when an implant of the same design is used but with a larger plate size. ${ }^{28}$

Hypotony and choroidal detachment occurred in $17.8 \%$ and $42.8 \%$ of the participants in the FP7 group. These figures were comparable with those reported by previous studies; these early changes were transient and did not influence the overall clinical outcome. ${ }^{7,15}$ 
Transient hypotony occurred in the FP7 group because the valve has a smooth surface area and because encapsulation takes a longer time to occur. Despite this, the flow restriction created by the valve, along with its small size, will prevent progressive hypotony. It is because of these factors that the AGV is considered to be safer than the Baerveldt valve.

The results of this study do not allow us to fully understand the hypertensive phase. Our data indicated the existence of a hypertensive phase when the IOP was higher than $21 \mathrm{mmHg}$ during the first 3 months after surgery, but then declined thereafter. However, IOP varied widely across different participants, and within each of the groups; this phenomenon has also been reported commonly in the literature. ${ }^{11,22,29-33}$ We did, however, detect a significant difference in bleb morphology when compared between the two groups. This may have been related to the high incidence of Tenon's cyst formation in the group of patients treated with the polypropylene-based AGV.

Several authors have proposed that the adjunctive use of anti-metabolites with glaucoma implants may be beneficial. ${ }^{34}$ In the present study, we used mitomycin-c in both the S2 and FP7 groups during surgery. However, the adjunctive use of mitomycin-c after surgery remains controversial. Further studies are now required to fully determine whether the adjunctive use of mitomycin-c is beneficial, and to demonstrate how this treatment might be utilized best during AGV implantation. ${ }^{35}$

We believe that the aspiration of fluid from a bleb, or surgical revision in combination with anti-metabolites, could improve the functionality of an encapsulated drainage implant. We refused to carry out repeat needling with 5-Fluorouracil (5-FU) to break fibrous tissue and prevent early-forming fibrinous proliferations.

AGV surgery is a major surgical procedure; consequently, patients experience psychological trauma if they are subject to repetitive interventions. We chose to use glaucoma medication in order to avoid the fluctuations in IOP fluctuation that occur with needling and 5-FU injections. Valve encapsulation is the same as an encysted bleb, and the aqueous humor that continually bathes the capsule may be loaded with vaso-proliferative factors, that could prevent the development of thin capsules. ${ }^{36}$

We found that neovascular glaucoma was a clear risk factor for valve failure in the S2 group, as reported previously in the literature. ${ }^{37}$ Prior trabeculectomy status was not a risk factor for either of the two forms of the valve. We also tested a range of other potential risk factors for failure, including younger age, and African descent; none of these variables could be counted as a risk factor. Previous studies, investigating other risk factors, such as poor conjunctival health, and long-standing antiglaucoma medication, also failed to demonstrate a statistical association between these factors and the risk of valve failure. ${ }^{38}$ Our analyses detected late corneal oedema in two cases from the S2 group; these corneal oedemas were not related to tube-corneal touch. Rather, this condition was related to persistently high and uncontrolled IOP. ${ }^{39}$

The participants of this study all suffered from advanced glaucoma, and other pathologies, including vein occlusion, vitreous haemorrhage, macular oedema, and corneal graft surgery. Consequently, our emphasis was to control IOP and vision stability in the S2 and FP7 groups, rather than focussing on disc examination and visual field function.

Performing a follow-up study with disc mapping, and by plotting the visual field, could be difficult and unwise. In the present study, the exposure of implants resulted in focal erosion of the tube through the overlying tissues (the donor sclera and the conjunctiva).

\section{Study Limitations}

The results arising from our present study, involving two types of AGV, to not provide us with an overall conclusion because of the fact that our patients had a range of different pathologies that were treated in a non-randomized manner, such as neovascular glaucoma, aphakic glaucoma, and advanced developmental glaucoma. The IOP is a valuable clinical value for monitoring the development of glaucoma and is a quantifiable variable. However, despite this, the main goal of glaucoma therapy is to preserve visual function. Unfortunately, the poor baseline visual acuity of our current cohort of students made the analysis of visual fields very difficult; the follow-up period was also very limited.

\section{Conclusion}

We found that both the S2 and FP7 AGVs were effective in lowering IOP and reducing the need for glaucoma medications. We found no clinical difference between these two AGVs with regard to mean IOP, success rate, or the prevalence of complications, when evaluated at one-year follow-up. These two types of AGV had a similar size but were constructed with different materials. Furthermore, we found that Bleb encapsulation was responsible for failure rate and the need for glaucoma medication in both the S2 
and FP7 groups. Ahmed valves are associated with a high risk of failure when considered as a first-line therapy for cases experiencing trabeculectomy.

\section{Acknowledgments}

The authors would like to acknowledge Dr Safaa M Saleh for helping to write the first draft of this manuscript.

\section{Disclosure}

None of the authors have any conflicts of interests to declare.

\section{References}

1. Assaad MH, Baerveldt G, Rockwood EJ. Glaucoma drainage devices: pros and cons. Curr Opin Ophthalmol. 1999;10:147-153. doi:10.1097/00055735-199904000-00012

2. Schocket SS. Investigations of the reasons for success and failure in the anterior shunt-to-the-encircling-band procedure in the treatment of refractory glaucoma. Trans Am Ophthalmol Soc. 1986;84:74 3-798.

3. Minckler DS, Shammas A, Wilcox M, et al. Experimental studies of aqueous filtration using the Molteno implant. Trans Am Ophthalmol Soc. 1987;85:368-392.

4. Wilcox MJ, Minckler DS, Odgen TE. Pathophysiology of artificial aqueous drainage in primate eyes with Molteno implants. J Glaucoma. 1994;3:140-151. doi:10.1097/00061198-199400320-00008

5. Prata JA Jr, Mermoud A, La Bree L, et al. In vitro and in vivo flow characteristics of glaucoma drainage implants. Ophthalmol. 1995;102:894-904. doi:10.1016/S0161-6420(95)30937-2

6. Ayyala RS, Zurakowski D, Smith JA, et al. A clinical study of the Ahmed glaucoma valve implant in advanced glaucoma. Ophthalmol. 1998;105(10):1968-1976. doi:10.1016/S0161-6420(98)91049-1

7. Coleman AL, Smyth RJ, Wilson MR, et al. Initial clinical experience with the Ahmed Glaucoma Valve implant in pediatric patients. Arch Ophthalmol. 1997;115(2):186-191. doi:10.1001/archopht.1997.01100 150188007

8. Gil-Carrasco F, Salinas-van Orman E, Recillas-Gispert C, et al. Ahmed valve implant for uncontrolled uveitic glaucoma. Ocul Immunol Inflamm. 1998;6(1):27-37. doi:10.1076/ocii.6.1.27.8078

9. Huang MC, Netland PA, Coleman AL, et al. Intermediate-term clinical experience with the Ahmed Glaucoma Valve implant. Am J Ophthalmol. 1999;127(1):27-33. doi:10.1016/S0002-9394(98)00394-8

10. Topouzis F, Coleman AL, Choplin N, et al. Follow-up of the original cohort with the Ahmed glaucoma valve implant. Am J Ophthalmol. 1999;128(2):198-204. doi:10.1016/S0002-9394(99)00080-X

11. Ayyala R, Jill D, Monshizadeh S, et al. A clinical study of the Ahmed Glaucoma Valve implant. Adv Glaucoma Ophthalmol. 1998;105: 1968-1976.

12. Eisenberg DL, Koo EY, Hafner G, et al. In vitro flow properties of glaucoma implant devices. Ophthalmic Surg Lasers. 1999;30:66 2-667.

13. Francis BA, Cortes A, Chen J, et al. Characteristics of glaucoma drainage implants during dynamic and steady-state flow conditions. Ophthalmol. 1998;105:1708-1714. doi:10.1016/S0161-6420(98)99042-X

14. Coleman AL, Hill R, Wilson MR, et al. Initial clinical experience with the Ahmed Glaucoma Valve implant. Am $J$ Ophthalmol. 1995;120:23-31. doi:10.1016/S0002-9394(14)73755-9

15. Costa VP, Azuara-Blanco A, Netland PA, et al. Efficacy and safety of adjunctive mitomycin $\mathrm{C}$ during Ahmed Glaucoma Valve implantation: a prospective randomized clinical trial. Ophthalmol. 2004;11 1:1071-1076. doi:10.1016/j.ophtha.2003.09.037
16. Hong $\mathrm{CH}$, Arosemena A, Zurakowski D, et al. Glaucoma drainage devices: a systemic literature review and current controversies. Surv Ophthalmol. 2005;50:48-60. doi:10.1016/j.survophthal.2004.10. 006

17. Ayyala RS, Harman LE, Michelini-Noris B, et al. Comparison of different biomaterials of the glaucoma drainage devices. Arch Ophthalmol. 1999;117:233-236. doi:10.1001/archopht.117.2.233

18. Ayyala RS, Michelini-Noris B, Flores A, et al. Comparison of different biomaterials of the glaucoma drainage device: part 2 . Arch Ophthalmol. 2000;118:1081-1084. doi:10.1001/archopht.11 8.8.1081

19. Law SK, Nguyen A, Coleman AL, et al. Comparison of safety and efficacy between silicone and polypropylene Ahmed glaucoma valves in refractory glaucoma. Ophthalmol. 2005;112:1514-1520. doi:10. 1016/j.ophtha.2005.04.012

20. Khan AO, Al-Mobarak F. Comparison of polypropylene and silicone Ahmed valve survival 2 years following implantation in the first 2 years of life. Br J Ophthalmol. 2009;93(6):791-794. doi:10.1136/ bjo.2008.151258

21. Gedde J, Schiffman C, Feuer J, et al. Treatment outcomes in the tube versus trabeculectomy study after one year of follow-up. Am J Ophthalmol. 2007;143:9-22. doi:10.1016/j.ajo.2006.07.020

22. Nouri-Mahdavi K, Caprioli J. Evaluation of the hypertensive phase after insertion of the Ahmed Glaucoma Valve. Am J Ophthalmol. 2003;136:1001-1008. doi:10.1016/S0002-9394(03)00630-5

23. Thieme H, Choritz L, Rummelt C, et al. Histopathologic findings in early encapsulated blebs of young patients treated with the Ahmed Glaucoma Valve. J Glaucoma. 2011;20:246-251. doi:10.1097/ IJG.0b013e3181e080ef

24. Jacob JT, Burgoyne CF, McKinnon SJ, et al. Biocompatibility response to modified Baerveldt glaucoma drains. J Biomed Mater Res. 1998;43:99-107. doi:10.1002/(ISSN)1097-4636

25. Boswell CA, Noecker RJ, Mac M, et al. Evaluation of an aqueous drainage glaucoma device constructed of ePTFE. $J$ Biomed Mater Res. 1999;48:591-595. doi:10.1002/(SICI)1097-4636(1999) 48:5<591::AID-JBM1 $>3.0 . C O ; 2-9$

26. Lai J, Poon A, Chua J, et al. Efficacy and safety of the Ahmed Glaucoma Valve implant in Chinese eyes with complicated glaucoma. Br J Ophthalmol. 2000;84:718-721. doi:10.1136/bjo.84. 7.718

27. Ishida K, Netland PA, Costa VP, et al. Comparison of polypropylene and silicone Ahmed Glaucoma Valves. Ophthalmol. 2006;11 3:1320-1326. doi:10.1016/j.ophtha.2006.04.020

28. Heuer DK, Lloyd MA, Abrams DA, et al. Which is better? One or two? A randomized clinical trial of single plate versus double plate Molteno implantation for glaucomas in aphakia and pseudophakia. Ophthalmol. 1992;99:1512-1519. doi:10.1016/S0161-6420(92)31772-5

29. Tsai J, Johnson C, Dietrich M. The Ahmed shunt versus the Baerveldt shunt for refractory glaucoma: a single-surgeon comparison of outcome. Ophthalmol. 2003;110:1814-1821. doi:10.1016/S0161-642 0(03)00574-8

30. Syed HM, Law SK, Nam SH, et al. Baerveldt-350 implant versus Ahmed valve for refractory glaucoma: a case-controlled comparison. J Glaucoma. 2004;13:38-45. doi:10.1097/00061198-200402000-00 008

31. Wang J, See J, Chew P. Experience with the use of Baerveldt and Ahmed glaucoma drainage implants in an Asian population. Ophthalmol. 2004;111:1383-1388. doi:10.1016/j.ophtha.2003.11. 005

32. Kee C. Prevention of early postoperative hypotony by partial ligation of silicone tube in Ahmed glaucoma valve implantation. J Glaucoma. 2001;10:466-469. doi:10.1097/00061198-200112000-00005

33. Wilson M, Mendis U, Paliwal A, et al. Long-term follow-up of primary glaucoma surgery with Ahmed glaucoma valve implant versus trabeculectomy. Am J Ophthalmol. 2003;136:464-470. doi:10. 1016/S0002-9394(03)00239-3 
34. Costa P, Azuara-Blanco A, Netland P, et al. Efficacy and safety of adjunctive mitomycin $\mathrm{C}$ during Ahmed Glaucoma Valve implantation. A prospective randomized clinical trial. Ophthalmology. 2004;111(6):1071-1076. doi:10.1016/j.ophtha.2003.09.037

35. Zhou M, Wang W, Huang W, et al. Use of mitomycin C to reduce the incidence of encapsulated cysts following Ahmed glaucoma valve implantation in refractory glaucoma patients: a new technique. $B M C$ Ophthalmol. 2014;14:107. doi:10.1186/1471-2415-14-107

36. Susanna R, Latin American Glaucoma Society (LAGS) Investigators. Partial Tenon's capsule resection with adjunctive mitomycin $\mathrm{C}$ in Ahmed glaucoma valve implant surgery. $\mathrm{Br} J$ Ophthalmol. 2003;87:994-998. doi:10.1136/bjo.87.8.994
37. Lavin MJ, Franks WA, Wormald RP, et al. Clinical risk factors for failure in glaucoma tube surgery. A comparison of three tube designs. Arch Ophthalmol. 1992;110:480-485. doi:10.1001/archopht.1992.01 080160058030

38. Broadway DC, Chang LP. Trabeculectomy, risk factors for failure and the preoperative state of the conjunctiva. $J$ Glaucoma. 2001;10:237-249. doi:10.1097/00061198-200106000-00017

39. Souza C, Tran D, Loman J, et al. Long-term outcomes of Ahmed Glaucoma Valve implantation in refractory glaucomas. Am J Ophthalmol. 2007;144:893-900. doi:10.1016/j.ajo.2007.07.035

\section{Publish your work in this journal}

Clinical Ophthalmology is an international, peer-reviewed journal covering all subspecialties within ophthalmology. Key topics include: Optometry; Visual science; Pharmacology and drug therapy in eye diseases; Basic Sciences; Primary and Secondary eye care; Patient Safety and Quality of Care Improvements. This journal is indexed on PubMed

Submit your manuscript here: https://www.dovepress.com/clinical-ophthalmology-journal
Central and CAS, and is the official journal of The Society of Clinical Ophthalmology (SCO). The manuscript management system is completely online and includes a very quick and fair peer-review system, which is all easy to use. Visit http://www.dovepress.com/ testimonials.php to read real quotes from published authors. 